\title{
Monitoring of Seahorse Populations, in the Ria Formosa Lagoon (Portugal), Reveals Steep Fluctuations: Potential Causes and Future Mitigations
}

\author{
Miguel Correia $^{1,2}$ (D)
}

Received: 25 February 2021/Revised: 13 September 2021/Accepted: 18 September 2021/Published online: 30 November 2021

(C) The Author(s) 2021

\begin{abstract}
After seahorse population fluctuations were revealed in previous studies, probably due to changes in their natural habitat, this study sought to determine the current status of the populations of the two existing seahorse species in the Ria Formosa lagoon, by revisiting previously surveyed sites, while assessing the main drivers for detected changes. Hippocampus guttulatus densities decreased significantly between 2002 and 2008, followed by a significant increase between 2008 and 2012 and a significant decrease between 2012 and 2018. There were no significant differences in $\mathrm{H}$. guttulatus populations between the 2002 and 2012 surveys, and between 2008 and 2018. As for Hippocampus hippocampus, there were no significant differences comparing densities from all the different dates. Among the different variables tested in this study, holdfast coverage seems to have played a crucial role in seahorse decline. It is important to further assess the impact on seahorse populations of two recently reported events, the illegal fishing of seahorses and the expansion of $\mathrm{Cau}$ lerpa prolifera algae in the Ria Formosa lagoon, South Portugal. Considering the existent threats and the probable causes behind the recent seahorse abundance decline, seahorses' low densities make them even more susceptible to local extirpation due to continuous threats, which emphasizes the dire urgency to put in place mitigative
\end{abstract}

Miguel Correia

mjtcorreia@gmail.com

1 CCMAR, Centro de Ciências Do Mar, Universidade Do Algarve, Campus de Gambelas, 8005-139 Faro, Portugal

2 Project Seahorse, Fisheries Centre, The University of British Columbia, 2202 Main Mall, Vancouver, BC V6T 1Z4, Canada actions to contribute to the conservation of these iconic species.

Keywords Illegal trade - Population trend - Marine protected areas · Hippocampus guttulatus - Hippocampus hippocampus

\section{Introduction}

Seahorses (Hippocampus spp.) typically live in coastal shallow areas around the world (Scales 2010; Vincent et al. 2011a; Yasué et al. 2012). They have a sparse distribution, low mobility, small home ranges, low fecundity, lengthy parental care and mate fidelity, which make them vulnerable to anthropogenic disturbances and habitat loss (Foster and Vincent 2004). They inhabit mostly corals, seagrasses, mangroves and estuaries or lagoon habitats and have been recognized as important predators of benthic animals (Tipton and Bell 1988). The acknowledgment of their vulnerability has led to the inclusion of seahorse species in the Convention on International Trade in Endangered Species of Wild Fauna and Flora (CITES) and in the International Union for Conservation of Nature (IUCN) Red List of Threatened Species. Currently, of the existing 45 seahorse species (Lourie et al. 2016; Short et al. 2018, 2020), 14 species are considered as threatened ("Vulnerable" or "Endangered"), and 17 are still classified as "Data Deficient" according to the latest IUCN Red List assessment (IUCN 2020). Seahorses are important in ecological, economical, medicinal, and cultural terms (Chen et al. 2015; Foster et al. 2019b; Koldewey and MartinSmith 2010). In some countries, subsistence fishers rely on seahorse trade as a significant portion of their annual income (Pajaro and Vincent 2015; Vincent et al. 2007) for 
use as ornaments, curios and traditional medicine (Vincent et al. 2011b).

The Ria Formosa lagoon, located in South Portugal, is a highly productive ecosystem for a variety of commercial species with high economic value (Ribeiro et al. 2006). The Ria Formosa is a Natural Park and some fishing gears are permitted and can have an impact on non-targeted species either by by-catch or through habitat degradation. Moreover, increases in illegal fishing activities (beam-trawl) have been reported recently in the Ria Formosa (pers. obs). This lagoon has been documented to harbour the densest seahorse populations ever recorded globally of two cooccuring species, the long-snouted seahorse (Hippocampus guttulatus) and the short-snouted seahorse (Hippocampus hippocampus), during 2000-2002 (Curtis and Vincent 2005). However, past research taken place between 2008 and 2009 revealed a steep decrease in abundance of $H$. guttulatus and $H$. hippocampus, of 94 and $73 \%$ respectively, while fishing pressure was absent (Caldwell and Vincent 2012). The seahorse population has since then been monitored and a slight recovery was reported between 2010 and 2013 (Correia et al. 2015a). From all the variables studied, holdfast availability seemed to have been the driver behind this fluctuation (Correia et al. 2015a). Considering that both species are classified in the IUCN red list as "Near Threatened" in the Mediterranean and "Data Deficient" in their global distribution (Pollom 2016; Pollom 2017; Woodall 2017), it is important to update the current status of the two existing seahorse species' populations, in this particular environment.

Seahorses have been historically caught, either directly or indirectly, from small-scale fisheries (hand collectors) to commercial shrimp trawlers (as bycatch) and are mostly sold in the Traditional Chinese Medicine (TCM), as curios or for aquaria display (Foster et al. 2019a; Koldewey and Martin-Smith 2010). In 2016, there were reports (mostly anecdotal) of illegal catches directly targeting seahorses for TCM in the Ria Formosa lagoon, using beam-trawl devices (https://tinyurl.com/y9zko9oo). Bottom trawling has been reported to reduce the structural complexity of benthic communities, affecting epifauna and altering the sediment formation (Collie et al. 2000; Tuck et al. 1998; Watling and Norse 1998). Fishing with bottom trawling gears has the potential to cause population declines in some species vul nerable to exploitation, such as seahorses (Casey and Myers 1998; Kaiser et al. 1998). Baum et al. (2003) sug gested that demersal fishing, responsible for bycatch of seahorses (Hippocampus erectus), has the potential to dif ferentially affect cohorts, disrupt social structure, reduce reproduction, damage habitat, and kill individuals. Due to its furtive nature, it is difficult to determine the extent of the illegal trade. Moreover, assessing changes in habitat, holdfast availability and seahorse abundance are critical to understand population trends.

Understanding the causes of seahorses' population fluctuations can provide important insight when considering adequate management plans and conservation actions. The objectives of the present study were to: (i) assess seahorses population density of $H$. guttulatus and $H$. hippocampus; (ii) describe the population structure and holdfast use of $H$. guttulatus and $H$. hippocampus; (iii) investigate both specie's population trend comparing the respective densities with previous studies; (iv) identify variables that are correlated with each species' abundance.

\section{Material and Methods}

\section{Seahorses' Population Surveys}

In order to determine the seahorse's population trend, 16 sites located in the Ria Formosa Lagoon, south Portugal $\left(36^{\circ} 59^{\prime} \mathrm{N} ; 7^{\bigcirc} 51^{\prime} \mathrm{W}\right)$ were surveyed by SCUBA Underwater Visual Census (UVC) from March to June 2018. The 16 selected sites were at the same GPS location as in previous studies (Caldwell and Vincent 2012; Correia et al. 2015a; Curtis and Vincent 2005) to allow for direct comparison (Fig. 1).

The UVC method used was the same as described in these studies, i.e. three $30 \mathrm{~m}$ transect tapes were used, covering a $180 \mathrm{~m}^{2}$ area per site (Caldwell and Vincent 2012; Correia et al. 2015a; Curtis and Vincent 2005). To optimize visibility conditions, all surveys were done during high slack tides when the water currents are weaker. A Garmin ${ }^{\circledR} 78 \mathrm{~s}$ GPS unit was used to determine the locations of each study area and the same bearing was taken while laying each transect so that the same area could be consistently covered on each sampling occasion. As in the previous surveys, whenever a seahorse was found, divers collected data regarding species, gender and height (according to Lourie et al. (1999)) along with three environmental variables: water depth and water temperature at depth (recorded using Divesoft ${ }^{\circledR}$ FREEDOM Basic NITROX dive computer), and the percentage of holdfasts coverage (i.e. the percentage of the holdfast present within a $1 \mathrm{~m}^{2}$ quadrat centred around the seahorse-either living or non-living material). In case no seahorse was found, an area of $1 \mathrm{~m}^{2}$ was surveyed each $10 \mathrm{~m}$ of each transect to allow habitat description ( $\%$ holdfast coverage).

\section{Seahorses' Population Abundance Trend and Environmental Correlations}

In order to determine if seahorse densities (HhDens for $H$. hippocampus and HgDens for $H$. guttulatus) had changed 
Fig. 1 Location of the 16 sites surveyed for seahorses during 2002, 2008, 2012 and 2018

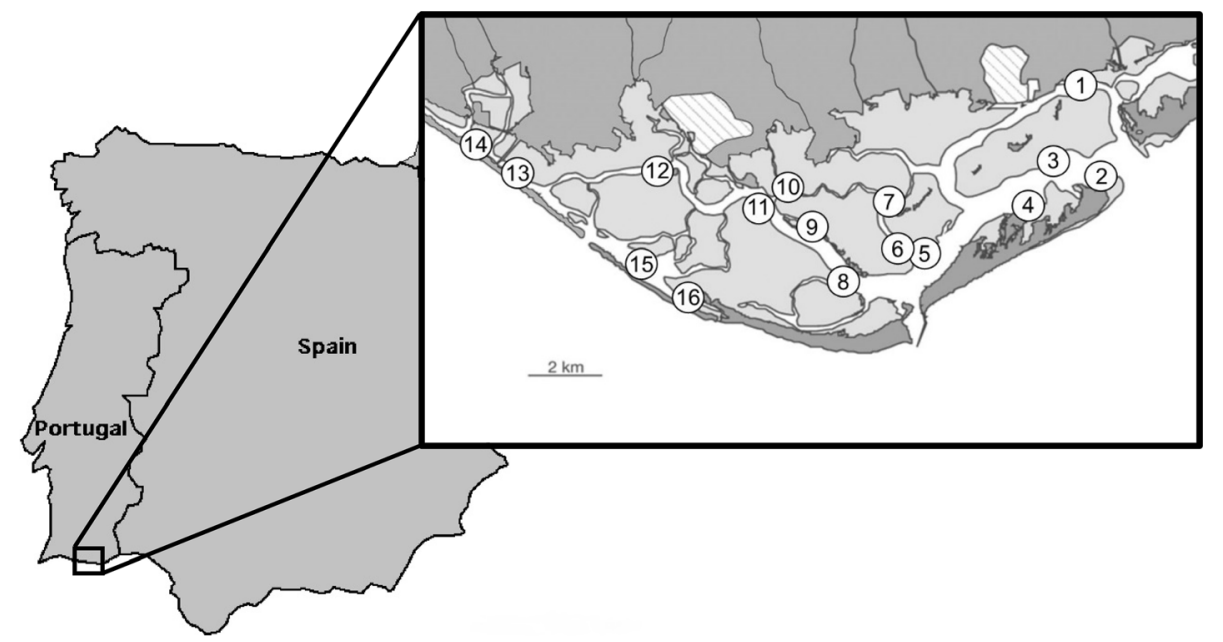

over time, seahorse densities from both species were compared with previous studies in 2001-2002 (Curtis and Vincent 2005), 2008-2009 (Caldwell and Vincent 2012) and 2010-2013 (Correia et al. 2015a). Seahorse densities reported in the present study were compared for all sites $(n=16)$ and time periods. To find out if there are significant changes between the different time periods, a Shapiro test for normality was performed. As densities presented a non-normal distribution, a non-parametric Friedman test was applied to find out if there are differences among the four groups. As Friedman test revealed differences among the survey periods for both species, a Wilcoxon signed rank post-hoc test with Bonferroni corrections was run to determine differences between each survey period (shapiro.test, friedman.test and wilcox_test functions in the stats R package; R Core Team; www.r-project.org).

In order to test if differences between survey periods are correlated with changes in environmental variables (Temp-Temperature, Depth—Depth and PerHoldfastPercentage of holdfast), a Shapiro test for normality was applied for each of the response and fixed variables. As most variables presented a non-normal distribution (except for Temperature), a Spearman rank correlation test was applied to determine potential correlations between all variables (shapiro.test and rcorr functions in the stats $R$ package; R Core Team; www.r-project.org). Statistical tests were performed using R-Sudio ${ }^{\circledR}$ software. As sug gested by Curtis and Vincent (2005), population sizes were estimated by extrapolating mean densities to the subtidal area (minimum area covered by water during spring tides according to Andrade (1990)—14.1 km2). Confidence intervals (95\% CI) were estimated for each sampling event by bootstrapping the density estimates according to Efron and Tibshirani (1994).

\section{Results}

A total of 40 seahorses were sighted during this study at 6 sites and were absent on the remaining 10 sites (Fig. 2). Hippocampus guttulatus was the most sighted species ( $\mathrm{n}=33$ ), while $H$. hippocampus only accounted for $17 \%$ of the total sightings ( 3 in Site 9, 2 in Site 5 and 1 in Site 3 and 1 in Site 4). Hippocampus guttulatus was marginally male-biased $(54.5 \%)$. The sex ratio was not calculated for $H$. hippocampus due to low numbers $(\mathrm{n}=7)$. After pooling all sites, the mean density was $0.009(\mathrm{SE} \pm 0.005)$ ind $\mathrm{m}^{-2}$ for $H$. guttulatus and 0.002 ( $\mathrm{SE} \pm 0.001$ ) ind $\mathrm{m}^{-2}$ for $H$. hippocampus (Table 1). Maximum density reported for $H$. guttulatus in study was observed in Site 3 with a density of 0.083 ind $\mathrm{m}^{-2}$, while $H$. hippocampus had the highest density of 0.013 ind $\mathrm{m}^{-2}$ in Site 9. Population estimates were performed based on the densities calculated for each sampling event and are presented in Table 2.

Temperature at depth averaged $16 \pm 1{ }^{\circ} \mathrm{C}$ during the survey period. Underwater horizontal visibility was considered to be moderate as it was greater than $1 \mathrm{~m}$ and did not have any negative impact on seahorse detection. Water depth varied from 1 to $8 \mathrm{~m}$. Considering the total area

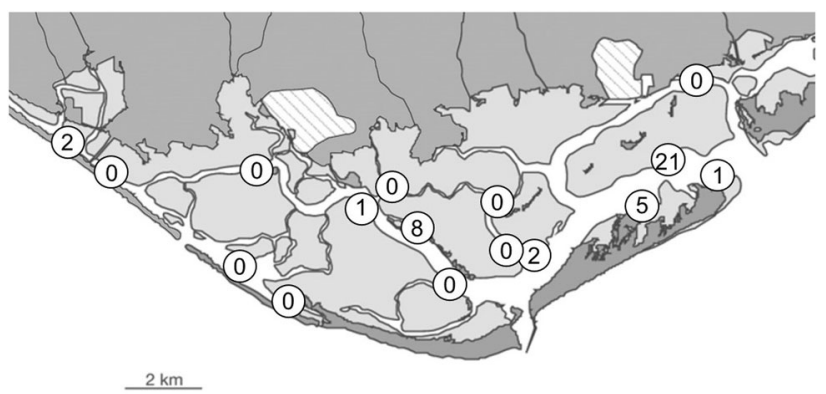

Fig. 2 Map of the Ria Formosa lagoon, Portugal showing the total number of seahorses at each of the 16 locations during underwater visual census surveys 
Table 1 Densities (mean and maximum) of two seahorse species in 16 sites surveyed in four time periods in the Ria Formosa lagoon

\begin{tabular}{|c|c|c|c|c|c|c|c|c|}
\hline & \multicolumn{4}{|c|}{ H. guttulatus } & \multicolumn{4}{|c|}{ H. hippocampus } \\
\hline & 2002 & 2008 & 2012 & 2018 & 2002 & 2008 & 2012 & 2018 \\
\hline Mean density $\left(/ \mathrm{m}^{2}\right)$ & 0.090 & 0.008 & 0.047 & 0.009 & 0.006 & 0.002 & 0.006 & 0.002 \\
\hline Maximum density $\left(/ \mathrm{m}^{2}\right)$ & 0.339 & 0.035 & 0.183 & 0.083 & 0.033 & 0.019 & 0.024 & 0.013 \\
\hline
\end{tabular}

Table 2 Abundance indices for Hippocampus guttulatus and $H$. hippocampus. $(\mathrm{CI}=$ bootstrap (1000x) estimated confidence limit)

\begin{tabular}{lllll}
\hline \multicolumn{5}{c}{ Abundance indices } \\
\cline { 2 - 5 } & \multicolumn{1}{c}{2002} & 2008 & 2012 & \multicolumn{2}{l}{2018} \\
\hline \multicolumn{4}{c}{ Hippocampus guttulatus } \\
Mean Density & 0.090 & 0.008 & 0.047 & 0.009 \\
N (estimated) & 1269000 & 110156 & 660937 & 121172 \\
Lower 95\% CI & 621810 & 32430 & 274950 & 21150 \\
Upper 95\% CI & 1964130 & 205860 & 593046 & 266490 \\
Hippocampus hippocampus & & & \\
Mean Density & 0.006 & 0.002 & 0.006 & 0.002 \\
N (estimated) & 78333 & 28559 & 80781 & 25703 \\
Lower 95\% CI & 25,380 & 5640 & 32,430 & 7050 \\
Upper 95\% CI & 149,460 & 67,680 & 139,590 & 47,940 \\
\hline
\end{tabular}

surveyed (pooling all sites), bottom coverage was dominated by barren areas of fine sand $(\sim 75 \%), 10.6 \%$ of shell fragments, $6.9 \%$ of tunicates, $3.8 \%$ of seagrasses ( $C y$ modocea nodosa and Zostera noltei), $2.5 \%$ of Caulerpa

Table 3 Environmental variables (temperature, depth and bottom coverage (\%)) at each site observed during the survey done in 2018

\begin{tabular}{llll}
\hline Site & Temp $\left({ }^{\circ} \mathrm{C}\right)$ & Depth $(\mathrm{m})$ & $\%$ Coverage \\
\hline 1 & 15 & 3 to 4 & $20 \%$ Tunicates \\
2 & 15 & 4 to 5 & $60 \%$ Shells \\
3 & 17 & 5 to 7 & $40 \%$ Caulerpa \\
4 & 17 & 2 to 3 & $30 \%$ Seagrass \\
5 & 16 & 4 to 5 & $20 \%$ Tunicates \\
6 & 14 & 4 to 5 & $20 \%$ Shells \\
7 & 16 & 5 to 6 & $20 \%$ Tunicates \\
8 & 15 & 5 to 6 & $20 \%$ Shells \\
9 & 14 & 4 to 6 & $30 \%$ Shells \\
10 & 17 & 4 to 5 & $20 \%$ Tunicates \\
11 & 17 & 5 to 6 & $20 \%$ Shells \\
12 & 17 & 6 to 8 & $30 \%$ Artificial \\
13 & 17 & 1 to 2 & $100 \%$ Sand \\
14 & 17 & 2 to 4 & $20 \%$ Shells \\
15 & 17 & 2 to 3 & $30 \%$ Tunicates \\
16 & 17 & 2 to 4 & $30 \%$ Seagrass \\
\hline
\end{tabular}

prolifera and $1.9 \%$ of artificial structures (Table 3). As for relative abundance of holdfasts, shell fragments accounted for $41.3 \%$, tunicates for $26.8 \%$, seagrasses for $14.8 \%, C$. prolifera for $6.9 \%$ and artificial structures for $1.9 \%$. Hippocampus guttulatus was sighted using $C$. prolifera more often $(46.9 \%)$ as holdfast, while $H$. hippocampus were sighted using tunicates $42.9 \%$ of the times as holdfast (Fig. 3).

The surveys conducted in this study recorded seahorses' population fluctuations in comparison with previous studies. Although both species seem to have similar temporal

\section{HG holdfast use (\%)}

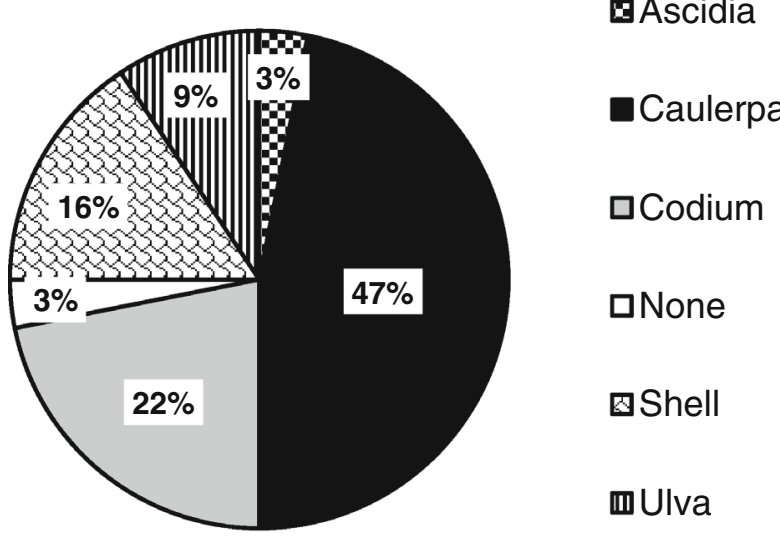

\section{HH holdfast use (\%)}

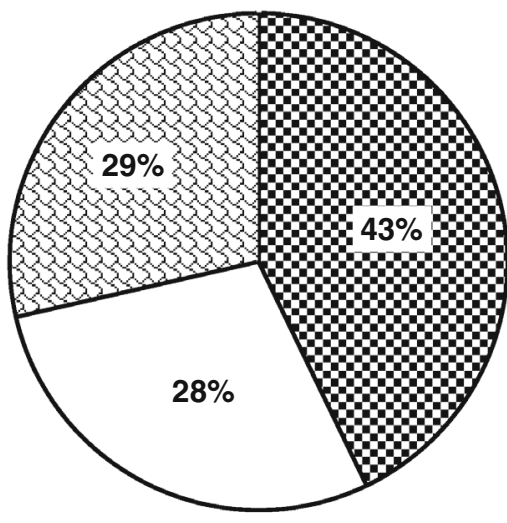

Ascidia

Caulerpa

口Codium

口None

囚Shell

mUlva

Fig. 3 Holdfast use (\%) of H. guttulatus (top) and H. hippocampus (bottom) when sighted in the 16 sites surveyed during the underwater visual census 
changes (Fig. 4), the Friedman test revealed significant differences in $H$. guttulatus over time, among the 16 sites (Friedman test, $\mathrm{Fr}=29.37$, d.f. $=3, P<0.0001$ ), and no significant differences for $H$. hippocampus (Friedman test, $\mathrm{Fr}=9.39$, d.f. $=3, P>0.05)$. Post-hoc tests revealed differences in $H$. guttulatus densities and no significant differences in H. hippocampus densities (Table 4). Although mean densities of $H$. hippocampus appeared to follow a similar pattern as $H$. guttulatus, the fact that they were consistently found at lower densities makes it harder to detect significant changes in abundance.

The results of the Spearman rank correlations were examined using Bonferroni corrections to adjust for multiple comparisons based on an alpha value of 0.05 (Fig. 5). A significant positive correlation was observed between HgDens and HhDens ( $\mathrm{rs}=0.53, p<0.0001,95 \% \mathrm{CI}$ ), indicating a moderate effect size and indicates that as HgDens increases, HhDens tends to increase. A significant positive correlation was observed between HgDens and PerHoldfast ( $\mathrm{rs}=0.53, p<0.001,95 \% \mathrm{CI}$ ), indicating a

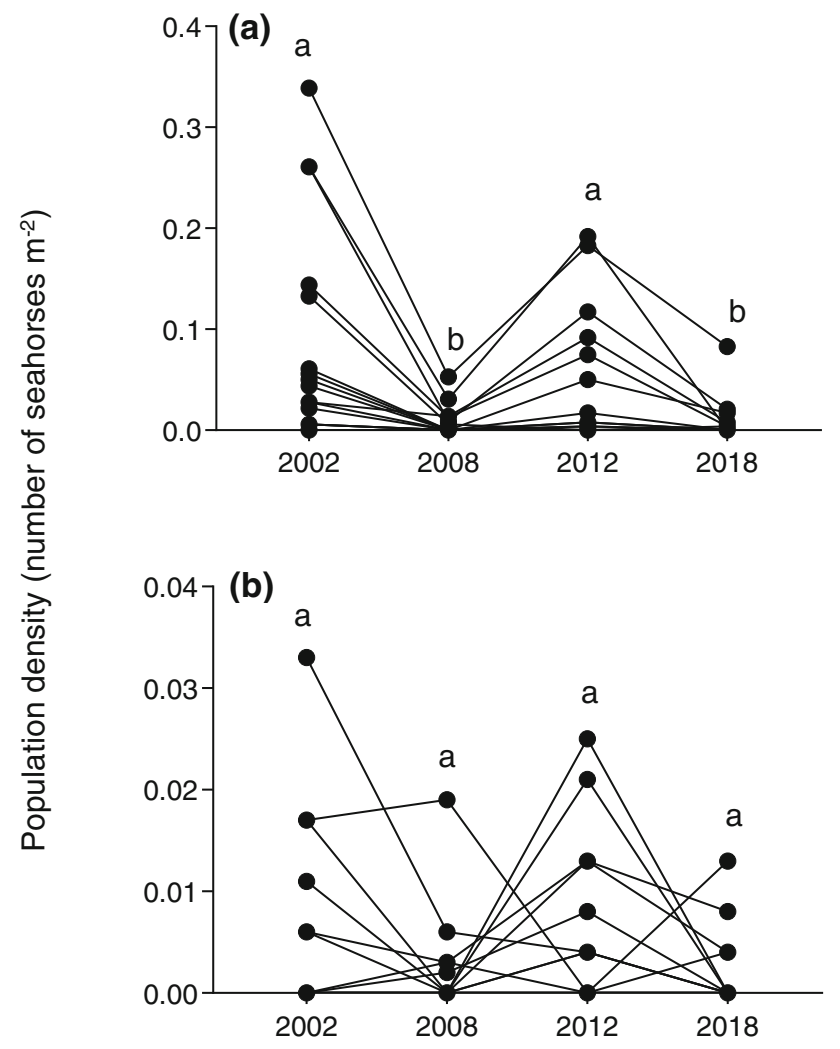

Survey time period

Fig. 4 Comparisons of a Hippocampus guttulatus and b Hippocampus hippocampus densities found during four underwater visual census survey periods of 16 sites $(-)$ in the Ria Formosa Lagoon. Sites and surveys with the same lower-case letter are not significantly different (i.e. Wilcoxon signed rank post hoc test $>0.05$ ) moderate effect size and indicates that as PerHoldfast increases, $\mathrm{HgDens}$ tends to increase. No other significant correlations were found.

\section{Discussion}

This study reported a sharp decline in seahorses populations in the Ria Formosa lagoon since the last population census done during 2010 and 2013 (Correia et al. 2015a). When comparing data from Curtis and Vincent (2005) with data from this study, seahorses' populations in the Ria Formosa lagoon were estimated to have decreased by $90 \%$ for $H$. guttulatus and $67 \%$ for H. hippocampus, from 2001 to 2018. The variations in seahorse abundance are made clear by looking at the population estimates. These estimates however are most probably over-estimating the real population size, as it is based on the subtidal area of the Ria Formosa lagoon. In addition, Correia et al. (2018b) suggest that seahorses rely on key environmental variables such as holdfast availability, depth and temperature, and habitat types that are not present in this entire subtidal area of the Ria Formosa lagoon. Globally, previously reported seahorse declines were not found to be directly associated with any particular variable (Freret-Meurer and Andreata 2008; Martin-Smith and Vincent 2005; Masonjones et al. 2010), while some studies found declines to be associated with changes in habitat availability (Correia et al. 2015a; Harasti 2016). Moreover, Correia et al. (2015a) suggested a positive relationship between the availability of holdfasts (natural or artificial) and $H$. guttulatus densities over time, which is similar to the results found in this study.

After pooling all sites in the study area, most of them (75\%) were bare substrate, consisting of fine sand and muddy flats. This is in line with the previous studyfrom Curtis and Vincent (2005) that reported $70 \%$ of bare seabed. Moreover, Curtis and Vincent (2005) reported seagrass as the main habitat for covered areas (58.6\%), followed by macro-algae (20.8\%) and invertebrates (17.8\%, of which $3.8 \%$ tunicates). Later, in 2012, Correia et al. (2018b) found that seahorses were likely to be present in areas where the bottom coverage consisted of $<20 \%$ tunicates and $>90 \%$ of shell fragments for $H$. hippocampus and areas with $>50 \%$ coverage of tunicates and shells for H. guttulatus, which agrees with this study's findings.

Seagrass beds have been declining over the last decades in the Ria Formosa, with a $75 \%$ reduction in the distribution of Z. noltei (Cunha et al. 2014). Some seahorse species have long been associated with seagrass beds as their preferred habitat (Bell et al. 2003; Curtis and Vincent 2005; Foster and Vincent 2004; Perante et al. 1998), so this decrease in seagrass coverage has a negative impact on seahorse abundance, particularly for $\mathrm{H}$. guttulatus (Ribeiro 
Table 4 Wilcoxon post-hoc test between seahorse density (HG-Hippocampus guttulatus; $\mathrm{HH}$-Hippocampus

hippocampus) and the different time periods (2002, 2008, 2012 and 2018)

\begin{tabular}{llllll}
\hline Species & Grouping & Statistic $(\mathrm{W})$ & $p$ & $p$ (adjusted) & Significance \\
\hline HG & 2002 vs 2008 & 120 & 0.001 & 0.004 & $* *$ \\
HG & 2002 vs 2012 & 100 & 0.025 & 0.149 & Not significant \\
HG & 2002 vs 2018 & 117 & 0.001 & 0.008 & $* *$ \\
HG & 2008 vs 2012 & 3 & 0.003 & 0.020 & $*$ \\
HG & 2008 vs 2018 & 17 & 0.944 & 1 & Not significant \\
HG & 2012 vs 2018 & 90 & 0.002 & 0.013 & $*$ \\
HH & 2002 vs 2008 & 30 & 0.107 & 0.642 & Not significant \\
HH & 2002 vs 2012 & 34 & 0.442 & 1 & Not significant \\
HH & 2002 vs 2018 & 33 & 0.236 & 1 & Not significant \\
HH & 2008 vs 2012 & 13 & 0.025 & 0.152 & Not significant \\
HH & 2008 vs 2018 & 18 & 1.000 & 1 & Not significant \\
HH & 2012 vs 2018 & 73 & 0.009 & 0.051 & Not significant \\
\hline
\end{tabular}

Fig. 5 Results of the Spearman rank correlation test (rho) between environmental variables and seahorse densities (TempDiff-Temperature; DepthDiff-Depth; PerHoldfastDiff-Percentage of holdfast; HhDensDiffHippocampus hippocampus density; HgDensDiffHippocampus guttulatus density)

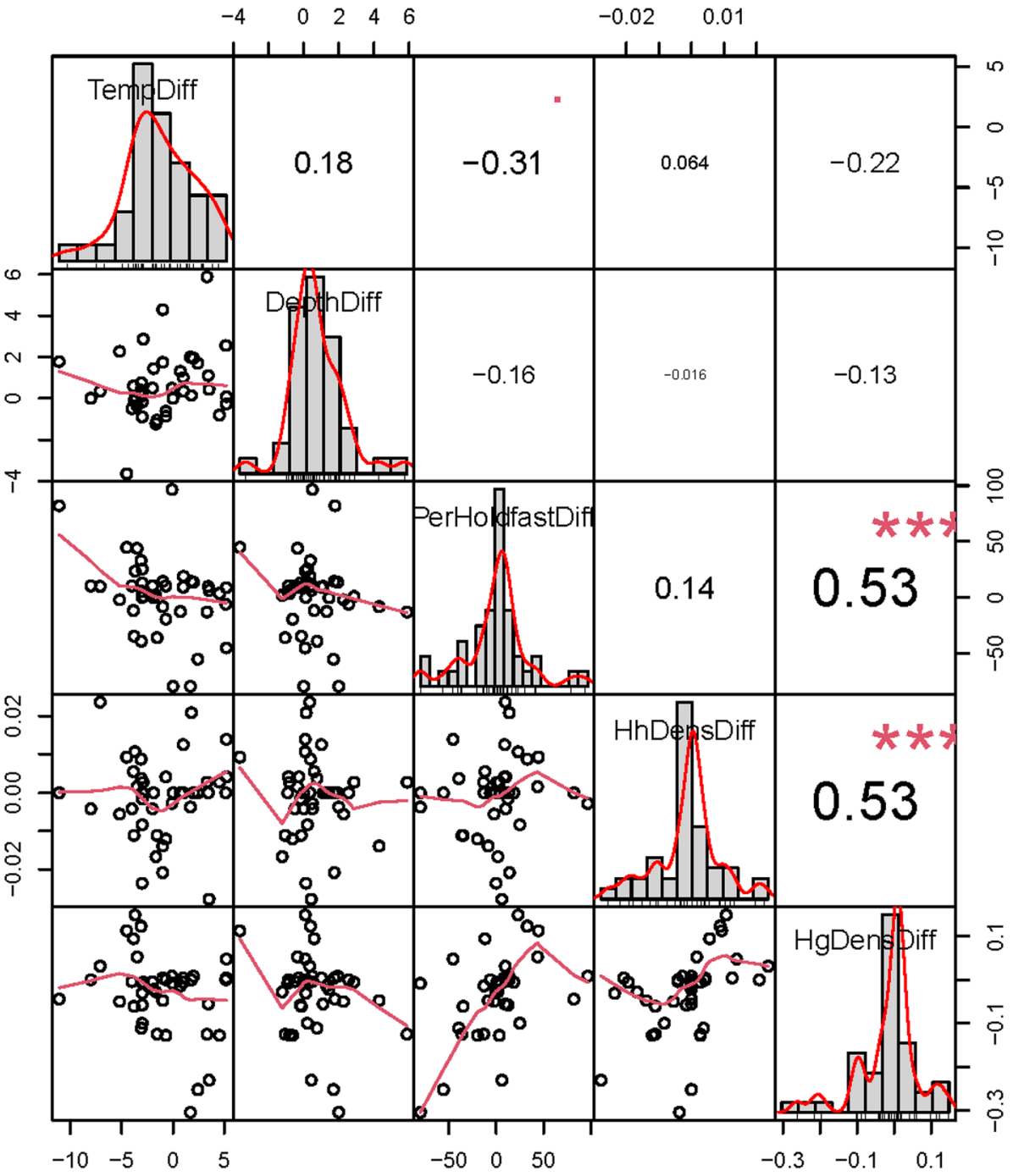

et al. 2006). However, seahorses have been reported to use alternative habitats as a response to seagrass depletion, in particular artificial structures (Claassens et al. 2018;
Correia et al. 2015b; Simpson et al. 2019), which highlights the capacity of seahorses to adapt to changes of natural habitats. Moreover, a new type of holdfast was available in 
the study area, not present in previous surveys, i.e. $C$. prolifera (Correia, pers. comm.). Caulerpa sp. is a marine opportunistic green algae with the capacity to rapidly colonize and change native assemblages (Klein and Verlaque 2008) while deteriorating sediment quality (Holmer et al. 2009). Although these algae have been sighted in the Ria Formosa in the past (Cunha et al. 2013), this sighting was restricted to a small patch outside the study area. The effects of the recently reported rapid spread of $C$. prolifera (Alexandre and Santos 2020; Parreira et al. 2021) on biodiversity, particularly on seahorses, are yet unknown. Possible consequences of this algae proliferation event include modifications of physical and chemical conditions (e.g. hydrodynamics and sediment deposition) having an impact on benthic assemblages (Deudero et al. 2014). In addition, studies indicate a negative correlation between the abundance of $C$. prolifera and $C$. nodosa meadows (Pérez-Ruzafa et al. 2012; Tuya et al. 2013), which have been reported has important habitat for $H$. guttulatus (Curtis and Vincent 2005). Conversely, C. prolifera has been reported has important habitat for fish and cephalopod species in the Mediterranean (Koulouri et al. 2016). Although this alga apparently provides extra holdfast availability, future research should assess the ecological impact on local seahorse populations.

Although this study suggests that holdfast availability seems to be related with seahorse abundance decline, other variables might also have negative impacts. The Ria Formosa bears a fairly large clam farming industry (Guimarães et al. 2012) and coastal constructions of man-made structures such as shipyards and harbours, and regular dredging activities. These activities are responsible for the extirpation of wide areas of seahorse habitat, such as seagrass meadows, and therefore are indirectly correlated with holdfast availability (Cunha et al. 2014). Additionally, there has also been an increase in reports of illegal fisheries in the Ria Formosa such as beam-trawling (Correia, pers. comm.) and beach seine (Erzini et al. 2002), which are responsible for catches of seahorses either directly or as bycatch. Due to their destructive nature, trawling is responsible for not only capturing small-sized animals, but also contributing to habitat degradation and removal (Duplisea et al. 2002; Stiles et al. 2010). Moreover, anecdotal information recently reported that illegal fisheries were targeting seahorses for the Traditional Chinese Medicine (TCM) trade, which was highlighted by a seizure of dried seahorses, in Malaga (Spain), illegally collected in the Ria Formosa lagoon.

Every year, about 37 million seahorses are estimated to be caught as bycatch in 22 countries (Lawson et al. 2017). The seahorse trade is often difficult to track, as it is often considered small-scale, both in terms of catches and economic value, which makes it difficult to have an accurate perception of the magnitude of the seahorse collection (Foster et al. 2016). There is a big knowledge gap in mapping illegal fishing of seahorses as they are mostly unreported and are not regulated (Zhang and Vincent 2019). Illegal fisheries may be responsible for high pressures on seahorse population, particularly in the Ria Formosa lagoon (Correia et al. 2015a; Zhang and Vincent 2019) and may be partially responsible for the population decline reported in this study and ultimately can lead to the local extirpation of seahorses.

To date, several mitigation actions have been proposed and implemented to study (Correia et al. 2018a, 2014) and recover wild seahorse populations through habitat enrichment (Correia et al. 2015b, 2013) in light of key habitat loss and degradation (Correia et al. 2015a, 2018b). Considering that seahorses have small home ranges (Caldwell et al. 2011; Caldwell and Vincent 2013), and that Andrade et al. (2016) reported up to $90 \%$ of recruitment found to be located up to $500 \mathrm{~m}$ from the original population, any continuous distress might seriously compromise the ability for population recovery, which may lead seahorses to the brink of local extirpation. In fact, extreme fluctuations of $>90 \%$, as reported in this study, leaves these populations vulnerable to any additional stressors during low density periods (Mace et al. 2008).

To avoid local extinction, other mitigation actions will therefore need to be considered, such as the protection of seahorse habitats (Vincent et al. 2011a); banning collection by providing seahorses with a conservation status (Harasti et al. 2014); the implementation of no-take marine protected areas (MPAs) (Harasti et al. 2014; Martin-Smith et al. 2004; Vincent et al. 2007) and other restriction policies. The benefits of MPAs for conserving marine biodiversity are well documented (Babcock et al. 2010; Halpern 2003; Lester et al. 2009; Roberts et al. 2001). However, information regarding the benefit of MPAs for conserving seahorse populations is still scarce (Harasti et al. 2014). Seahorse species have been found to have different levels of habitat reliance and preference (Zhang and Vincent 2018). As key habitat characteristics have been described for $H$. guttulatus and H. hippocampus in the Ria Formosa lagoon (Correia et al. 2018b), target protected areas should integrate these findings to ensure population recovery.

In light of the recent decline of both seahorse species in the Ria Formosa lagoon, it is of the utmost importance to implement rapid mitigation actions to cope with the emerging illegal capture and to allow for species recovery, while continue monitoring the wild populations. The implementation of no-access zone to allow for habitat and species recovery in conjunction with short-term habitat enrichment might provide the necessary conditions for seahorse populations to bounce back from the existing 
decline trend. Local stakeholders such as major decision makers, authorities, and socio-economic sector (e.g., marine tourism companies and local fishing communities) need to be included in the process in order to ensure the success and effectiveness of this action.

Acknowledgements This is a contribution from Project Seahorse. The study was supported by Oceano Azul Foundation, which provided the necessary funds for the surveys within the scope of the "Save the seahorses of the Ria Formosa" campaign. This study received Portuguese national funds from FCT-Foundation for Science and Technology through project UID/Multi/04326/2019. I am grateful for the contribution of Dr. Jorge Palma, Céline Madeira and João Rodrigues in logistic and technical support and Dr. Iain Caldwell for his help in the statistical analysis.

Funding This study received Portuguese national funds from FCTFoundation for Science and Technology through project UID/Multi/ $04326 / 2019$

\section{Declarations}

Conflict of interest The authors declare that they have no conflicts of interest.

Ethical approval All applicable international, national, and institutional guidelines for the care and use of animals were followed.

Open Access This article is licensed under a Creative Commons Attribution 4.0 International License, which permits use, sharing, adaptation, distribution and reproduction in any medium or format, as long as you give appropriate credit to the original author(s) and the source, provide a link to the Creative Commons licence, and indicate if changes were made. The images or other third party material in this article are included in the article's Creative Commons licence, unless indicated otherwise in a credit line to the material. If material is not included in the article's Creative Commons licence and your intended use is not permitted by statutory regulation or exceeds the permitted use, you will need to obtain permission directly from the copyright holder. To view a copy of this licence, visit http://creativecommons. org/licenses/by/4.0/.

\section{References}

Alexandre, A., and R. Santos. 2020. High nitrogen and phosphorous acquisition by belowground parts of Caulerpa prolifera (Chlorophyta) contribute to the species' rapid spread in Ria Formosa lagoon, southern Portugal. Journal of Phycology 56 (3): 608-617. https://doi.org/10.1111/jpy.12988.

Andrade, J.P., C. Madeira, M. Correia, and J. Palma. 2016. Assigning Hippocampus guttulatus recruits to the populations of origin using microsatellites: rResults from a field study in the Ria Formosa (south Portugal). PeerJ Preprints 4: e1794v1. https:// doi.org/10.7287/peerj.preprints. $1794 \mathrm{v} 1$.

Babcock, R.C., N.T. Shears, A.C. Alcala, N.S. Barrett, G.J. Edgar, K.D. Lafferty, T.R. McClanahan, and G.R. Russ. 2010. Decadal trends in marine reserves reveal differential rates of change in direct and indirect effects. Proceedings of the National Academy of Sciences 107 (43): 18256. https://doi.org/10.1073/pnas. 0908012107.
Baum, J.K., J.J. Meeuwig, and A.C.J. Vincent. 2003. Bycatch of lined seahorses (Hippocampus erectus) in a Gulf of Mexico shrimp trawl fishery. Fish B-Noaa 101 (4): 721-731.

Bell, E.M., J.F. Lockyear, J.M. McPherson, A.D. Marsden, and A.C.J. Vincent. 2003. First field studies of an endangered South African seahorse. Hippocampus Capensis. Environ Biol Fish 67 (1): 35-46. https://doi.org/10.1023/A:1024440717162.

Caldwell, I.R., and A.C.J. Vincent. 2012. Revisiting two sympatric European seahorse species: Apparent decline in the absence of exploitation. Aquatic Conservation 22 (4): 427-435. https://doi. org/10.1002/Aqc.2238.

Caldwell, I.R., and A.C.J. Vincent. 2013. A sedentary fish on the move: Effects of displacement on long-snouted seahorse (Hippocampus guttulatus Cuvier) movement and habitat use. Environ Biol Fish 96 (1): 67-75. https://doi.org/10.1007/s10641-0120023-4.

Caldwell, I.R., M. Correia, J. Palma, and A.C.J. Vincent. 2011. Advances in tagging syngnathids, with the effects of dummy tags on behaviour of Hippocampus guttulatus. Journal of Fish Biology 78 (6): 1769-1785. https://doi.org/10.1111/j.10958649.2011.02983.x.

Casey, J.M., and R.A. Myers. 1998. Near extinction of a large, widely distributed fish. Science 281 (5377): 690-692. https://doi.org/10. 1126/science.281.5377.690.

Chen, L., X.Y. Wang, and B.K. Huang. 2015. The genus Hippocampus - A review on traditional medicinal uses, chemical constituents and pharmacological properties. Journal of Ethnopharmacology 162: 104-111. https://doi.org/10.1016/j. jep.2014.12.032.

Claassens, L., A.J. Booth, and A.N. Hodgson. 2018. An endangered seahorse selectively chooses an artificial structure. Environ Biol Fish 101 (5): 723-733. https://doi.org/10.1007/s10641-0180732-4.

Collie, J.S., S.J. Hall, M.J. Kaiser, and I.R. Poiner. 2000. A quantitative analysis of fishing impacts on shelf-sea benthos. Journal of Animal Ecology 69 (5): 785-798. https://doi.org/10. 1046/j.1365-2656.2000.00434.x.

Correia, M., J. Palma, H. Koldewey, and J.P. Andrade. 2013. Can artificial holdfast units work as a habitat restoration tool for longsnouted seahorse (Hippocampus guttulatus Cuvier)? Journal of Experimental Marine Biology and Ecology 448: 258-264. https://doi.org/10.1016/j.jembe.2013.08.001.

Correia, M., J. Palma, H. Koldewey, and J.P. Andrade. 2014. The use of a non-invasive tool for capture-recapture studies on a seahorse Hippocampus guttulatus population. Journal of Fish Biology 84 (4): 872-884. https://doi.org/10.1111/Jfb.12304.

Correia, M., I. Caldwell, H. Koldewey, J.P. Andrade, and J. Palma. 2015a. Seahorse (Hippocampinae) population fluctuations in the Ria Formosa Lagoon, south Portugal. Journal of Fish Biology 87 (3): 679-690. https://doi.org/10.1111/jfb.12748.

Correia, M., H. Koldewey, J.P. Andrade, and J. Palma. 2015b. Effects of artificial holdfast units on seahorse density in the Ria Formosa lagoon. Portugal. J Exp Mar Biol Ecol 471: 1-7. https://doi.org/ 10.1016/j.jembe.2015.05.012.

Correia, M., A. Campoy, C. Madeira, and J.P. Andrade. 2018a. Is filament clipping an effective tool for tissue sampling in Hippocampus guttulatus? Environ Biol Fish 101 (10): 1517-1523. https://doi.org/10.1007/s10641-018-0796-1.

Correia, M., H.J. Koldewey, J.P. Andrade, E. Esteves, and J. Palma. 2018b. Identifying key environmental variables of two seahorse species (Hippocampus guttulatus and Hippocampus hippocampus) in the Ria Formosa lagoon. South Portugal. Environ Biol Fish 101 (9): 1357-1367. https://doi.org/10.1007/s10641-0180782-7.

Cunha, A.H., J.F. Assis, and E.A. Serrão. 2014. Reprint of "Seagrasses in Portugal: A most endangered marine habitat." 
Aquatic Botany 115: 3-13. https://doi.org/10.1016/j.aquabot. 2014.02.007.

Cunha AH, Varelalvarez E, Paulo DS, Sousa I, Serrao E (2013) The rediscovery of Caulerpa prolifera in Ria Formosa, Portugal 60 years after the previous record. Cah Biol Mar 54(3): 359-364

Curtis, J.M.R., and A.C.J. Vincent. 2005. Distribution of sympatric seahorse species along a gradient of habitat complexity in a seagrass-dominated community. Marine Ecology-Progress Series 291: 81-91. https://doi.org/10.3354/meps291081.

Deudero, S., A. Box, M. Vázquez-Luis, and N.L. Arroyo. 2014. Benthic community responses to macroalgae invasions in seagrass beds: Diversity, isotopic niche and food web structure at community level. Estuarine, Coastal and Shelf Science 142: 12-22. https://doi.org/10.1016/j.ecss.2014.03.006.

Duplisea, D.E., S. Jennings, K.J. Warr, and T.A. Dinmore. 2002. A size-based model of the impacts of bottom trawling on benthic community structure. Canadian Journal of Fisheries and Aquatic Sciences 59 (11): 1785-1795. https://doi.org/10.1139/ f02-148.

Efron, B., and R.J. Tibshirani. 1994. An Introduction to the Bootstrap (1st ed.). Chapman and Hall/CRC. https://doi.org/10.1201/ 9780429246593

Erzini K, Bentes L, Coelho R, Correia C, Lino P, Monteiro P, Ribeiro J, Gonçalves J (2002) Recruitment of sea breams (Sparidae) and other commercially important species in the Algarve (Southern Portugal) Final report, Commission of the European Communities DG XIV/C/1

Foster, S.J., and A.C.J. Vincent. 2004. Life history and ecology of seahorses: Implications for conservation and management. Journal of Fish Biology 65 (1): 1-61. https://doi.org/10.1111/j. 1095-8649.2004.00429.x.

Foster, S., S. Wiswedel, and A. Vincent. 2016. Opportunities and challenges for analysis of wildlife trade using CITES data seahorses as a case study. Aquatic Conservation 26 (1): 154-172. https://doi.org/10.1002/aqc.2493.

Foster, S.J., T.C. Kuo, A.K.Y. Wan, and A.C.J. Vincent. 2019a. Global seahorse trade defies export bans under CITES action and national legislation. Marine Policy 103: 33-41. https://doi.org/ 10.1016/j.marpol.2019.01.014.

Foster, S.J., M.L. Stanton, A.C. Nellas, M.M. Arias, and A.C.J. Vincent. 2019b. The catch and trade of seahorses in the Philippines post-CITES, vol. 2, 45. Vancouver: University of British Columbia Library.

Freret-Meurer, N.V., and J.V. Andreata. 2008. Field studies of a Brazilian seahorse population, Hippocampus reidi Ginsburg. Brazilian Archives of Biology and Technology 51 (4): 743-751. https://doi.org/10.1590/S1516-89132008000400012.

Guimarães, M.H.M.E., A.H. Cunha, R.L. Nzinga, and J.F. Marques. 2012. The distribution of seagrass (Zostera noltii) in the Ria Formosa lagoon system and the implications of clam farming on its conservation. Journal for Nature Conservation 20 (1): 30-40. https://doi.org/10.1016/j.jnc.2011.07.005.

Halpern, B.S. 2003. The impact of marine reserves: Do reserves work and does reserve size matter? Ecological Applications 13 (1): 117-137. https://doi.org/10.1890/1051-0761(2003)013[0117: TIOMRD]2.0.CO;2.

Harasti, D. 2016. Declining seahorse populations linked to loss of essential marine habitats. Marine Ecology Progress Series 546: 173-181. https://doi.org/10.3354/meps11619.

Harasti, D., K. Martin-Smith, and W. Gladstone. 2014. Does a no-take marine protected area benefit seahorses? Plos One. https://doi. org/10.1371/journal.pone.0105462.

Holmer, M., N. Marbà, M. Lamote, and C.M. Duarte. 2009. Deterioration of sediment quality in seagrass meadows (Posidonia oceanica) invaded by macroalgae (Caulerpa sp). Estuar
Coast 32 (3): 456-466. https://doi.org/10.1007/s12237-0099133-4.

IUCN (2020) The IUCN Red List of Threatened Species Version 2020-1:http://www.iucnredlist.org. Downloaded on 23 April 2020.

Kaiser, M.J., D.B. Edwards, P.J. Armstrong, K. Radford, N.E.L. Lough, R.P. Flatt, and H.D. Jones. 1998. Changes in megafaunal benthic communities in different habitats after trawling disturbance. ICES Journal of Marine Science 55 (3): 353-361. https:// doi.org/10.1006/jmsc.1997.0322.

Klein, J., and M. Verlaque. 2008. The Caulerpa racemosa invasion: A critical review. Marine Pollution Bulletin 56 (2): 205-225. https://doi.org/10.1016/j.marpolbul.2007.09.043.

Koldewey, H.J., and K.M. Martin-Smith. 2010. A global review of seahorse aquaculture. Aquaculture 302 (3-4): 131-152. https:// doi.org/10.1016/j.aquaculture.2009.11.010.

Koulouri, P., S. Kalogirou, M. Maidanou, D. Koutsoubas, and C. Dounas. 2016. Fish and cephalopod assemblage structure of green alga Caulerpa prolifera (Chlorophyta) meadow in the eastern Mediterranean Sea (Elounda Bay, Crete Island). Regional Studies in Marine Science 3: 33-41. https://doi.org/10. 1016/j.rsma.2015.12.002.

Lawson, J.M., S.J. Foster, and A.C.J. Vincent. 2017. Low bycatch rates add up to big numbers for a genus of small fishes. Fisheries 42 (1): 19-33. https://doi.org/10.1080/03632415.2017.1259944.

Lester, S.E., B.S. Halpern, K. Grorud-Colvert, J. Lubchenco, B.I. Ruttenberg, S.D. Gaines, S. Airamé, and R.R. Warner. 2009. Biological effects within no-take marine reserves: A global synthesis. Marine Ecology Progress Series 384: 33-46. https:// doi.org/10.3354/meps08029.

Lourie, S.A., R.A. Pollom, and S.J. Foster. 2016. A global revision of the seahorses Hippocampus Rafinesque 1810 (Actinopterygii: Syngnathiformes): Taxonomy and biogeography with recommendations for further research. Zootaxa 4146 (1): 66. https:// doi.org/10.11646/zootaxa.4146.1.1.

Lourie SA, Vincent AC, Hall HJ (1999) Seahorses: an identification guide to the world's species and their conservation. Project Seahorse, London, UK

Mace, G.M., N.J. Collar, K.J. Gaston, C. Hilton-Taylor, H.R. AkÇAkaya, N. Leader-Williams, E.J. Milner-Gulland, and S.N. Stuart. 2008. Quantification of extinction risk: IUCN's system for classifying threatened species. Conservation Biology 22 (6): 1424-1442. https://doi.org/10.1111/j.1523-1739.2008.01044.x.

Martin-Smith, K.M., and A.C.J. Vincent. 2005. Seahorse declines in the Derwent estuary, Tasmania in the absence of fishing pressure. Biological Conservation 123 (4): 533-545. https:// doi.org/10.1016/j.biocon.2005.01.003.

Martin-Smith, K.M., M.A. Samoilys, J.J. Meeuwig, and A.C.J. Vincent. 2004. Collaborative development of management options for an artisanal fishery for seahorses in the central Philippines. Ocean Coast Manage 47 (3-4): 165-193. https:// doi.org/10.1016/j.oceoamann.2004.02.002.

Masonjones, H.D., E. Rose, L.B. McRae, and D.L. Dixson. 2010. An examination of the population dynamics of syngnathid fishes within Tampa Bay, Florida, USA. Curr Zool 56 (1): 118-133. https://doi.org/10.1093/czoolo/56.1.118.

Pajaro, M.G., and A.C.J. Vincent. 2015. The catch and export of the seahorse trade in the Philippines, pre-CITES. Fisheries Centre Working Report 1 (2): 27.

Parreira, F., B. Martínez-Crego, C.M. Lourenço Afonso, M. Machado, F. Oliveira, Manuel dos Santos, J. Gonçalves, and R. Santos. 2021. Biodiversity consequences of Caulerpa prolifera takeover of a coastal lagoon. Estuarine, Coastal and Shelf Science 255: 107344. https://doi.org/10.1016/j.ecss.2021.107344 
Perante, N.C., M.G. Pajaro, and A.C.J. Vincent. 1998. Demographics of the seahorse Hippocampus comes in the Central Philippines. Marine Biology of the South China Sea III: 439-448.

Pérez-Ruzafa, A., C. Marcos, C.M. Bernal, V. Quintino, R. Freitas, A.M. Rodrigues, M. García-Sánchez, and I.M. Pérez-Ruzafa. 2012. Cymodocea nodosa vs. Caulerpa prolifera: Causes and consequences of a long term history of interaction in macrophyte meadows in the Mar Menor coastal lagoon (Spain, southwestern Mediterranean). Estuarine, Coastal and Shelf Science 110: 101-115. https://doi.org/10.1016/j.ecss.2012.04.004.

Pollom, R. (2016) Hippocampus hippocampus The IUCN Red List of Threatened Species 2016: eT10069A54904826 Downloaded on 02 April 2020.

Pollom, R. (2017) Hippocampus guttulatus The IUCN Red List of Threatened Species 2017: eT41006A67617766. Downloaded on 02 April 2020

Ribeiro, J., L. Bentes, R. Coelho, J.M.S. Goncalves, P.G. Lino, P. Monteiro, and K. Erzini. 2006. Seasonal, tidal and diurnal changes in fish assemblages in the Ria Formosa lagoon (Portugal). Estuar Coast Shelf S 67 (3): 461-474. https://doi. org/10.1016/j.ecss.2005.11.036.

Roberts, C.M., J.A. Bohnsack, F. Gell, J.P. Hawkins, and R. Goodridge. 2001. Effects of marine reserves on adjacent fisheries. Science 294 (5548): 1920-1923. https://doi.org/10. 1126/science.294.5548.1920.

Scales, H. 2010. Advances in the ecology, biogeography and conservation of seahorses (genus Hippocampus). Progress in Physical Geography 34 (4): 443-458. https://doi.org/10.1177/ 0309133310364928.

Short, G., R. Smith, H. Motomura, D. Harasti, and H. Hamilton. 2018. Hippocampus japapigu, a new species of pygmy seahorse from Japan, with a redescription of $H$. pontohi (Teleostei, Syngnathidae). Zookeys 779 (779): 27-49. https://doi.org/10.3897/zoo keys.779.24799.

Short, G., L. Claassens, R. Smith, M. De Brauwer, H. Hamilton, M. Stat, and D. Harasti. 2020. Hippocampus nalu, a new species of pygmy seahorse from South Africa, and the first record of a pygmy seahorse from the Indian Ocean (Teleostei, Syngnathidae). ZooKeys 934: 141-156.

Simpson, M., R.L. Morris, D. Harasti, and R.A. Coleman. 2019. The endangered White's seahorse Hippocampus whitei chooses artificial over natural habitats. Journal of Fish Biology 95 (2): 555-561. https://doi.org/10.1111/jfb.14002.

Stiles M, Stockbridge J, Lande M, Hirshfield M Impacts of Bottom Trawling on Fisheries, Tourism, and the Marine Environment. In, 2010.

Tipton, K., and S.S. Bell. 1988. Foraging patterns of two syngnathid fishes: Importance of harpacticoid copepods. Marine EcologyProgress Series 47: 31-43. https://doi.org/10.3354/meps047031.
Tuck, I.D., S.J. Hall, M.R. Robertson, E. Armstrong, and D.J. Basford. 1998. Effects of physical trawling disturbance in a previously unfished sheltered Scottish sea loch. Marine Ecology Progress Series 162: 227-242. https://doi.org/10.3354/ meps162227.

Tuya, F., H. Hernandez-Zerpa, F. Espino, and R. Haroun. 2013. Drastic decadal decline of the seagrass Cymodocea nodosa at Gran Canaria (eastern Atlantic): Interactions with the green algae Caulerpa prolifera. Aquatic Botany 105: 1-6. https://doi. org/10.1016/j.aquabot.2012.10.006.

Vincent, A.C.J., J.J. Meeuwig, M.G. Pajaro, and N.C. Perante. 2007. Characterizing a small-scale, data-poor, artisanal fishery: Seahorses in the central Philippines. Fisheries Research 86 (2-3): 207-215. https://doi.org/10.1016/j.fishres.2007.06.006.

Vincent, A.C.J., S.J. Foster, and H.J. Koldewey. 2011. Conservation and management of seahorses and other Syngnathidae. Journal of Fish Biology 78 (6): 1681-1724. https://doi.org/10.1111/j. 1095-8649.2011.03003.x.

Vincent ACJ, Giles BG, Czembor CA, Foster SJ, (eds) (2011b) Trade in seahorses and other syngnathids in countries outside Asia (1998-2001), vol 19, Fisheries Centre, University of British Columbia [ISSN 1198-6727]

Watling, L., and E.A. Norse. 1998. Disturbance of the seabed by mobile fishing gear: A comparison to forest clearcutting. Conservation Biology 12 (6): 1180-1197. https://doi.org/10. 1046/j.1523-1739.1998.0120061180.x.

Woodall L (2017) Hippocampus hippocampus. The IUCN Red List of Threatened Species 2017: e.T10069A67618259. https://doi.org/ 10.2305/IUCN.UK.2017-3.RLTS.T10069A67618259.en. Down loaded on 02 April 2020.,

Yasué, M., A. Nellas, and A.C.J. Vincent. 2012. Seahorses helped drive creation of marine protected areas, so what did these protected areas do for the seahorses? Environmental Conservation 39 (2): 183-193. https://doi.org/10.1017/S0376892911 000622.

Zhang, X., and A.C.J. Vincent. 2018. Predicting distributions, habitat preferences and associated conservation implications for a genus of rare fishes, seahorses (Hippocampus spp). Divers Distrib 24 (7): 1005-1017. https://doi.org/10.1111/ddi.12741.

Zhang, X., and A.C.J. Vincent. 2019. Using cumulative humanimpact models to reveal global threat patterns for seahorses. Conservation Biology 33 (6): 1380-1391. https://doi.org/10. 1111/cobi.13325.

Publisher's Note Springer Nature remains neutral with regard to jurisdictional claims in published maps and institutional affiliations. 